\title{
Predicting changes in language skills between 2 and 3 years in the EDEN mother-child cohort
}

Objective: To examine the factors predicting changes in language skills between 2 and 3 years. Methods: By using longitudinal data concerning 1002 children from the EDEN study, linear regression was used to predict 3-year language performance from 2-year language performance and the risk factors associated with language delays. Logistic regressions were performed to examine two change trajectories: children who fall below the 10th percentile of language skills between 2 and 3 years (declining trajectory), and those who rose above the 10th percentile (resilient trajectory). Results: The final linear model accounted for $43 \%$ of the variance in 3-year language scores, with 2-year language scores accounting for $22 \%$.

Exposure to alcohol during pregnancy, earlier birth term, lower level of parental education and lower frequency of maternal stimulation were associated with the declining trajectory. Breastfeeding was associated with the resilient trajectory. Conclusions: This study provides a better understanding of the natural history of early language delays by identifying biological and social factors that predict changes in language skills between the ages of 2 and 3 years. 
1 Predicting changes in language skills between 2 and 3 years in the EDEN mother-child cohort

3 Hugo Peyre ${ }^{1,2}$, MD, Jonathan Y. Bernard ${ }^{3,4}$, PhD, Anne Forhan ${ }^{3,4}$, MPH, Marie-Aline Charles ${ }^{3,4}$,

4 MD, PhD, Maria De Agostini ${ }^{3,4}, \mathrm{PhD}$, Barbara Heude ${ }^{3,4}, \mathrm{PhD}$, Franck Ramus ${ }^{1}, \mathrm{PhD}$, on behalf of 5 the EDEN Mother-Child Cohort Study Group.

6

71 Laboratoire de Sciences Cognitives et Psycholinguistique, Ecole Normale Supérieure, CNRS, 8 EHESS, Paris, France.

92 Hôpital Robert Debré, Service de Psychopathologie de l'Enfant et de l'Adolescent, APHP, Paris,

10 France.

113 Inserm, Centre for research in Epidemiology and Population Health (CESP), U1018,

12 Epidemiology of diabetes and renal diseases lifelong approach team, F-94807, Villejuif, France.

134 University Paris-Sud, UMRS 1018, F-94807, Villejuif, France.

15 Address correspondence: Hugo Peyre, MD, LSCP, Département d'Etudes Cognitives, Ecole

16 Normale Supérieure, 29 rue d'Ulm, 75005 Paris, France. Email: peyrehugo@yahoo.fr. Phone:

$17 \quad 0033(0) 144322619$. 
25 Short title: Predicting changes in language between $2 \& 3$ years.

27 Abbreviations:

28 CDI-2: MacArthur-Bates Communicative Development Inventory at 2 years.

29 EDEN: Etude des Déterminants pré et postnatals précoces du développement et de la santé de 30 l'ENfant.

31 LC-3: Language skills at 3 years.

33 Key words: language delays, longitudinal study, child, preschool, trajectory 
50 For some children, a very limited expressive vocabulary at 2 years is the first indication of a

51 persistent language impairment (Rice, Taylor, \& Zubrick, 2008). Early identification of these

52 children could lead to effective interventions to improve their social integration and academic

53 performance (Law, Garrett, \& Nye, 2003). However, several longitudinal studies have reported

54 that language skills in toddlerhood only poorly predict subsequent language outcome (Bishop et 55 al., 2003; Dale et al., 2003; Feldman et al., 2005; Reilly et al., 2010; Henrichs et al., 2011; Law et 56 al., 2012). Even when the biological and environmental factors typically associated with language 57 delays were added in the models, the prediction accuracy was low.

59 In a large Dutch sample, Henrichs et al. (2011) reported that the receiver operating characteristic 60 (ROC) curve using CDI-N (Dutch version of the MacArthur-Bates Communicative Development 61 Inventory) expressive vocabulary scores at 18 months to predict LDS (Language Development 62 Survey ; expressive vocabulary skills) delay status at 30 months had an Area Under the Curve 63 (AUC) of 0.74 , indicating only moderate predictive value. In a small study including 113 64 children, Feldman et al. (2005) reported slightly higher AUC (0.79) between CDI scores at 2 and 653 years. In the Generation R study (Henrichs et al., 2011), most children delayed at 18 months on 66 the CDI-N scored in the normal range at 30 months on the LDS (positive predictive value $=29 \%$ ) 67 and most children delayed at 30 months had not scored below the $10^{\text {th }}$ percentile at 18 months 68 (sensitivity $=30 \%$ ). These findings are similar to those of Westerlund, Berglund, \& Eriksson 69 (2006), who reported that the positive predictive value from the Swedish version of the CDI at 18 70 months was only $17.6 \%$ and that half the children delayed at 3 years of age had not been delayed 71 at 18 months. Dale et al. (2003) and Feldman et al. (2005) reported higher positive predictive 72 values (44\% and 64\%, respectively) and sensitivity (39\% and 50\%, respectively) when language 73 delay at 2 and 3 years of age were cross-tabulated, yet more than half the children with an 
74 expressive language delay at 3 years of age in these studies had not been delayed at 2 years of 75 age.

76 The picture improves only slightly when taking into account factors typically associated with

77 language delays. In the Generation R study (Henrichs et al., 2011), when maternal age and 78 education, marital status, family income, child ethnicity, parenting stress, gestational age, birth 79 weight, child gender and age and 18-months vocabulary scores were used in a linear regression to 80 predict LDS scores at 30 months, the model accounted for only $17.7 \%$ of the variance, with 18 81 months vocabulary scores accounting for $11.5 \%$.

82 In the Early Language in Victoria Study (Reilly et al., 2010), when relying on both earlier 83 measures of language at 2 years and the risk factors typically associated with language delays, 84 statistical models predicted $30.4 \%$ of the variance of expressive language skills at 4 years, with 85 late talking status at 2 years accounting for 9.5\%. Reilly et al. (2010) also investigate the extent to 86 which the effects of various risk factors vary across development. Biological influences on

87 language outcomes were found to be strong at 2 years, but social disadvantage became 88 increasingly important at age 4.

90 In sum, although many children show a discontinuity in the development of their language skills

91 between 2 and 3 years, early communication was the best predictor of subsequent language

92 functioning. Because of this discontinuity, the identification of the factors predicting trajectory 93 changes, that is, children whose language performances vary between two time points (i.e., those

94 who fall below the $10^{\text {th }}$ percentile of language skills between two time points: the declining 95 trajectory, and those who rose above the $10^{\text {th }}$ percentile: the resilient trajectory) raise particular 96 interest. In an article using data from children $(n=13,016)$ of the Millennium Cohort Study by

97 Law et al. (2012), children were categorized into four groups: a Typical Language (TL) group 98 scoring within normal limits at both times points; an Increasingly Vulnerable Language (IVL) 
99 group with a score below the norm only at the second time point; a Resilient Language (RL)

100 group with a score below the norm only at the first time point and a Consistently Low Language

101 (CLL) group with language delay with a score below the norm at both time points. Law et al.

102 (2012) examined changes in language skills between 3 and 5 years. Among other results, that

103 study indicated that a higher educational level of the mother was associated with the resilient

104 trajectory (i.e., maternal education significantly distinguished CLL and RL groups). Between 18

105 and 30 months, the risk factors associated with the declining trajectory have been specifically

106 studied by Henrichs et al. (2011). Children in the IVL group were more likely to have mothers

107 with younger ages and a low educational level, and to come from families with non-western

108 parents and more parenting stress than children in the TL group. That study also reported that

109 children in the RL group (called late bloomers) were more likely to have mothers with older ages,

110 to come from families with non-western parents and to have lower gestational ages than children

111 in the TL group.

112

113 In the present study, we examine the factors that predict change in language skills in a large 114 sample of children between 2 and 3 years of age. In 2006, the US Preventive Services Task Force

115 review examined the predictors of speech and language delays in preschool-aged children

116 (Nelson et al., 2006). The most consistently reported risk factors included a family history of

117 speech and language delay, male gender, and perinatal factors. Other risk factors reported less

118 consistently included educational levels of the mother and father, birth order, and family size. In

119 the present study, we also considered tobacco and alcohol consumption during pregnancy,

120 maternal age at birth and breastfeeding because they are well established determinants of

121 cognitive development (Farah et al., 2008; O’Leary et al., 2009; Whitehouse et al., 2011; Bernard

122 et al., 2013). 
124 We specifically aimed to address the following questions:

125 - Question 1: To what extent can language skills at 3 years be predicted from language

126 skills at 2 years and from typical risk factors? As reported by previous studies, we expect

127 language skills at 2 years to only poorly predict language skills at 3 years

128 (sensitivity $<50 \%$ ), and we expect a statistical model relying on language score at 2 years

129 and the risk factors typically associated with language delays to predict no more than $50 \%$

130 of the variance of language scores at 3 years, with language scores at 2 years explaining a

$131 \quad$ large amount of this variance.

132 - Question 2: What are the major risk factors associated with changes in language skills

133 between 2 and 3 years? In particular, what are the risk factors differentiating children

134 whose performance changes over time, i.e. showing resilient or increasingly vulnerable

135 language, from those whose performance remains stable (consistently low and typical

$136 \quad$ language respectively)?

139 Method

141 Data source

142 Mother-child pairs were recruited as part of the EDEN prospective mother-child cohort study

143 (http://eden.vjf.inserm.fr). The primary aim of the EDEN cohort was to identify prenatal and

144 early postnatal nutritional, environmental and social determinants associated with children's

145 health and their normal and pathological development. Pregnant women seen for a prenatal visit

146 at the departments of Obstetrics and Gynecology of the University Hospitals of Nancy and

147 Poitiers before their twenty-fourth week of amenorrhea were invited to participate. Exclusion

148 criteria were personal history of diabetes, multiple pregnancies, intention to deliver outside the 
149 university hospital or to move out of the study region within the next 3 years, and inability to

150 speak French. The participation rate among eligible women was estimated to be 55\%. Enrolment

151 started in February 2003 in Poitiers and in September 2003 in Nancy; it lasted 27 months in each

152 center and allowed the inclusion of 2002 women. Compared to the national perinatal survey

153 carried out on 14,482 women who delivered in France in 2003 (Blondel et al., 2006), women

154 included in the EDEN study had similar socio-demographic characteristics except that they were

155 more educated and more often employed (details of the EDEN study protocol have been

156 described in Drouillet et al., 2009).

157 A very broad range of data on each child's environment and development were collected from

158 obstetrical records, questionnaire and neuropsychological tests (Drouillet et al., 2009).

159 The study was approved by the ethical research committee (Comité consultatif de protection des

160 personnes dans la recherche biomédicale) of the Hospital of Bicêtre, and by the Data Protection

161 Authority (Commission Nationale de l'Informatique et des Libertés). Informed written consents

162 were obtained from the parents at enrollment for themselves and for the newborn after delivery.

163 Of the 2002 singleton pregnant women participating in the EDEN prospective mother-child 164 cohort study, 1002 children were included in the analysis (Table 1 and Figure 1).

166 Variables

167 Risk factors

168 Child factors

169 In the EDEN cohort, gender, gestational age and birth weight were collected from obstetrical

170 records. Of the 1002 children included in the analysis, 52\% were male and $48 \%$ were female.

171 Mean ( \pm SD) birth weight and birth term were $3.3( \pm 0.49) \mathrm{kg}$ and $39.3( \pm 1.65)$ years

172 respectively.

173 
175 Mothers completed questionnaires on maternal age at birth and alcohol and tobacco consumption

176 during pregnancy. In our sample, mean maternal age at birth was $29.5( \pm 4.7)$ years, $8 \%$ of the

177 mothers reported more than 3 units of alcohol per week during pregnancy and $21 \%$ reported

178 tobacco consumption during pregnancy.

179

180 Family history of speech and language delay

181 Mothers and fathers completed questionnaires on history of speech and language delay. $12 \%$ of

182 the children included in the analysis had at least one parent with a history of speech and language 183 delay.

185 Breastfeeding

186 Of the 1002 children included in the analysis, $73 \%$ were breastfed for at least 3 days 187 (breastfeeding initiation) and the mean duration of breastfeeding (including both partial and 188 exclusive breastfeeding) was $4.7( \pm 3.7)$ weeks.

190 Child environmental factors

191 Mothers and fathers completed questionnaires on family income during pregnancy ( $>3000$ 192 euros/months vs. 2300 to 3000 euros/months vs. $<2300$ euros/months), parental education (mean 193 of maternal and paternal school years) and the child's caretaker (mothers reported the main 194 caretaker in the 2-year questionnaire: mother, family (father, grandparents), nursery and others 195 (child minder, neighbor)). We further included an estimate of maternal cognitive stimulation (by 196 averaging the weekly frequencies of storytelling, singing and playing with the child, as reported 197 by mothers at 2 and 3 years). Birth order (number of older siblings in three classes: 0,1 or more 198 than 1), bilingualism (yes vs. no), the child's entry to pre-elementary school (yes vs. no; and the 
199 date of the child's entry to pre-elementary school if applicable) and the recruitment center were

200 also considered in the analysis. Descriptive statistics of the participants are shown in Table 1.

201

202 Language Measures

203 2 year-old Language Measure

204 At 24 months of age, parents completed the short French version of the MacArthur-Bates 205 Communicative Development Inventory [CDI-2] (Kern, 2003; Kern et al., 2010). Parents were 206 asked to indicate from a list of 100 words if their child could say the word spontaneously 207 (expressive vocabulary). Scores are the number of words produced by the child. The 208 psychometric properties of the short French version of the MacArthur-Bates Communicative 209 Development Inventory at 24 months have been analyzed by Kern et al. (2010), showing high 210 test-retest reliability and strong associations with the corresponding scores from the complete 211 version.

212

213 3 year-old Language Measures

214 Trained psychologists individually assessed each child at 3 years by using neuropsychological 215 tests from the ELOLA (Evaluation du Langage Oral de L'enfant Aphasique) (De Agostini et al., 216 1998) and NEPSY (A Developmental NeuroPSYchological Assessment) (Kemp, Kirk, \& 217 Korkman, 2001; Korkman M, Kirk U, \& Kemp S, 2003) batteries.

218 Five tests were used:

219 - Semantic fluency (ELOLA), which was scored as the sum of the number of animals 220 named in one minute and of the number of objects named in one minute. As can be seen 221 in Table 1, the mean score on the Semantic fluency test was 6.83 words $( \pm 3.94)$. 
- Word and nonword repetition (ELOLA), scored as the number of words (6 items) and nonwords (6 items) repeated correctly. In our sample, the mean score on the Word and nonword repetition test was 7.60 words $( \pm 3.24)$.

- Sentence comprehension (NEPSY), a sentence comprehension task requiring pointing at one amongst 8 pictures, was scored as the number of correct answers (13 items, e.g., "montre-moi un grand lapin" ["show me a large rabbit"]). The mean score on this test was $8.63( \pm 2.96)$.

- Sentence repetition (NEPSY) scored as the number of sentences (17 items, e.g., "dors bien" ["sleep well"]) repeated correctly. The mean score on this test was $7.21( \pm 3.35)$.

- Picture naming (ELOLA), scored as the number of pictures named correctly (10 items, e.g., "cheval" ["horse"]). The mean score on this test was $7.047 .04( \pm 1.32)$.

233 Since an exploratory factor analysis of the 5 variables yielded a single factor (first factor 234 eigenvalue $=2.63$; second factor eigenvalue $=0.65$ ) explaining $53 \%$ of the total variance and 235 having similar loadings on all variables (Semantic fluency $=0.52$, Word and nonword 236 repetition $=0.50$, Sentence comprehension $=0.53, \quad$ Sentence repetition $=0.57$, Picture 237 naming $=0.52)$, a single language component $(\mathrm{LC}-3)$ representing language skills at 3 years was 238 calculated as the mean of the five scores (each score was first converted into a z-score in order 239 for each test to have the same weight) (Table 1). The skewness (0.37) and kurtosis (0.17) of LC-3 240 indicate a normal distribution.

241 LC-3 was calculated if the number of missing scores was less than or equal to three ; this 242 inclusive strategy is justified by the fact that for three out of five tests, the data were not missing 243 at random, i.e., children with missing scores had significantly lower language performance 244 (similar results were found by Mäntynen et al. (2001)).

245 Because measures were not taken exactly on each child's birthday (mean age: $24.26 \pm 0.81$ and $24638.05 \pm 0.81$ months for CDI-2 and LC-3 respectively), both scores were linearly corrected for 
247 the actual age of the child (children had an average increase of about 5 words per month on the 2

248 year-old language measure and 0.16 standard deviation per month on the 3 year-old language 249 measure).

250 We defined children as being language-delayed if they were below the $10^{\text {th }}$ percentile (on CDI-2 251 or on LC-3); this arbitrary cut-off is in line with previous research (Dale et al., 2003; Henrichs et 252 al., 2011).

253

254 Exclusion criteria

255 The population includes all children without previously known conditions associated with speech 256 and language delay, such as hearing and neurological impairments (Figure 1).

\section{Attrition analysis of the children without exclusion criteria (see Supplementary Table)}

259 In this longitudinal study, the attrition rates were $29 \%$ at 2 years and $36 \%$ at 3 years.

260 Similar attrition and missing data rates were reported by Henrichs et al. (2011). In the Generation

261 R Study, 29\% of the children who had vocabulary scores at 2 years had missing language scores 262 at 30 months; in our study this rate was $26 \%$.

263 Compared to the 1031 children whose language scores at both ages were available, the 370 264 children with LC-3 only missing (due to attrition as well as other mechanisms) differed in several 265 determinants of language skills. In particular, they were more likely to have a family history of 266 language delay $(p<0.001)$ and they were less likely to attend school at 3 years $(p<0.001)$;

267 Moreover, they showed significantly lower language skills at 2 years $(p=0.004)$.

268 Compared to the 1401 children whose language scores at 2 years were available (CDI-2), the 485 269 children who had missing CDI-2 also differ in several determinants of language skills. In 270 particular, their mothers were younger $(p<0.001)$, more likely to smoke during pregnancy $271(p<0.001)$, and their parents had lower family income $(p<0.001)$ and lower educational level 
$272(p<0.001)$. Moreover, they were less likely to be the eldest child of the family and had a lower

273 frequency of maternal stimulation during the first 2 years.

274 In the Generation R Study, Henrichs et al. (2011) also found evidence of some selective bias due

275 to missing data (e.g., compare to children with vocabulary scores at both ages, children who had

276 missing language scores at 30 months were more likely to have a lower birth weight and less

277 likely to have mothers with high levels of education).

278

279 Statistical analysis

280 Question 1: Prediction of language skills at 3 years.

281 First, languages measures (CDI-2 and LC-3) were analyzed as quantitative variables. An

282 estimation of the coefficient of determination $\left(\mathrm{R}^{2}\right)$ was conducted in three linear regression

283 models: models A1 and A2: with CDI-2 and LC-3 (respectively) as the dependent variable and

284 the risk factors as independent variables; model A3: with LC-3 as the dependent variable and

285 CDI-2 and the risk factors as independent variables.

286 Second, prediction of language delay at 3 years given language level at 2 years was assessed by 287 examining sensitivity and specificity (CDI-2 as binary variable) and area under the ROC curve 288 (CDI-2 as continuous variable).

289 Question 2: Risk factors associated with changes in language skills between 2 and 3 years.

290 First, the risk factors associated with changes in language skills were examined in the model A3 291 described above.

292 Second, four patterns of change were determined following Law et al. (2012): a Typical

293 Language group (TL) scoring within normal limits at both 2 and 3 years; an Increasingly

294 Vulnerable Language (IVL) group with typical development at 2 years but language delay by 3

295 years; a Resilient Language (RL) group with language delay at 2 years but not anymore at 3 296 years; and a Consistently Low Language (CLL) group with language delay at both time points. 
Logistic regressions were performed to examine risk factors associated with two change profiles

298 (RL group compared to CLL group [model B1] and IVL group compared to TL group [model

299 B2]). Variables that showed some evidence $(p<0.15)$ of univariate association with the change

300 trajectories were entered into the multiple logistic regression models. The significance threshold

301 for removing variables was set at 0.15 (backward stepwise selection).

302 All statistical analyses were performed using SAS 9.2 software (SAS Institute, Cary, NC).

\section{Results}

Question 1: Table 2 shows the results of the regression analyses for the CDI-2 (model A1) and the LC-3 (model A2). Variance explained by risk factors increased slightly between 2 years

$308(15.6 \%)$ [model A1] and 3 years (21\%) [model A2], suggesting that these risk factors helped explain more variation in language skills at 3 years than at 2 years. The addition of CDI- 2 to

310 model A2 increased the variance of LC-3 explained from $21 \%$ to $43.4 \%$ [model A3]. Factors

311 associated with both CDI-2 and LC-3 included gender, breastfeeding initiation, birth term, child's

312 caretaker and frequency of maternal stimulation. Alcohol consumption was also significantly

313 associated with CDI-2 only; family history of language delay; parental education and pre-

314 elementary schooling were associated with LC-3 only.

315 Sensitivity of the CDI-2 to predict delayed children at 3 years was $41.0 \%$, the positive predictive

316 value of the CDI-2 to predict delayed children at 3 years was also $41.0 \%$ and the $\mathrm{AUC}=0.85$

317 (95\% CI: 0.81-0.88).

318 Question 2: While most risk factors had a significant influence on language skills at 2 and at 3 319 years [models A1 and A2], only some risk factors had an influence between 2 and 3 years: once 320 language level at 2 years was known, only male gender $(p=0.001)$, income $(p=0.04)$, level of 
321 parental education $(p<0.001)$ and frequency of maternal stimulation $(p=0.02)$ explained

322 additional variance at 3 years [model A3].

323 There were 41 children in the Consistently Low Language (CLL) group, 59 in the Resilient

324 Language (RL) group, 59 in the Increasingly Vulnerable Language (IVL) group and 843 in the

325 Typical Language (TL) group (Table 1). Model B1 indicated that only breastfeeding

326 distinguished between RL and CLL groups $(\mathrm{OR}=3.75$; IC-95\% $[1.60-8.78]$; p-value $=0.002)$

327 (Table 3). In the RL group 75\% were breastfed $(n=44$; among these children, the mean 328 breastfeeding duration $=4.15( \pm 3.35))$ whereas in the CLL group, only $44 \%$ were breastfed $(\mathrm{n}=$

329 18; mean breastfeeding duration $=4.69( \pm 4.19)$. In model B2, alcohol consumption during 330 pregnancy $(\mathrm{OR}=2.29$; IC-95\% [1.04-5.02]; $p=0.04)$, birth term $(\mathrm{OR}=0.81$; IC-95\% [0.71$3310.93] ; p<0.001)$, parental education ( $\mathrm{OR}=0.76$; IC-95\% [0.67-0.87]; $p<0.001)$ and frequency 332 of maternal stimulation $(\mathrm{OR}=0.52 ; \mathrm{IC}-95 \%[0.37-0.75] ; p=0.001)$ significantly differentiated 333 between IVL and TL groups.

\section{Discussion}

337 With respect to our first question, our ability to predict language skills at 3 years remains limited.

338 Indeed, linear models including a measure of language at 2 years and the main risk factors predict

339 only $43 \%$ of the variance of language at 3 years, with CDI- 2 scores at 2 years accounting for $34022 \%$. Our estimates of the variance explained are higher than those found in the Generation $\mathrm{R}$ 341 study (the model accounted for only $18 \%$ of the variance of LDS scores at 30 months, with 18342 months vocabulary scores accounting for 12\%) and in the Early Language in Victoria Study (30\%

343 of the variance of expressive language skills at 4 years was explained by the model, with late 344 talking status at 2 years accounting for 10\%), but this may be at least partly explained by the 345 shorter lag between the two time points in our study. Although language skills at 2 years have a 
346 fair predictive power of language skills at 3 years, more than half the children with an expressive

347 language delay at 3 years of age had not been delayed at 2 years of age (sensitivity $=41 \%$ ).

348 Regarding our ability to predict language skills at 3 years from language skills at 2 years, the

349 sensitivity, positive predictive value (41\%) and AUC (0.85) were similar to those of Feldman et

350 al. (2005).

351

352 In line with those studies, the best predictor of language functioning was found to be early

353 vocabulary (Question 2). Changes in language skills between the ages of 2 and 3 years was

354 influenced by gender (-0.16 SD in male) and several factors related to the child's environment:

355 the level of parental education $(+0.08 \mathrm{SD}$ per year $)$, income $(-0.11 \mathrm{SD}$ and $-0.17 \mathrm{SD}$ for incomes

$356<2300$ and between 2300 and 3000 euros/months compared to income $>3000$ euros/months) and

357 the frequency of maternal stimulations (+0.09 SD per unit).

358 We also identified risk (and protective) factors differentiating children whose performance 359 changed over time, i.e. showing resilient or increasingly vulnerable language, compared to those

360 whose performance remains stable (consistently low and typical language respectively). Children

361 who showed a declining trajectory between 2 and 3 years had increased exposure to alcohol

362 during pregnancy, lower level of parental education, earlier birth term and lower frequency of

363 maternal stimulation. On the other hand, breastfeeding increased the likelihood of having a

364 resilient trajectory. These are all well-known determinants of cognitive development among

365 young children. Less linguistically rich environments have been consistently associated to poorer

366 child language outcomes (Farah et al., 2008). In the Generation R study, (Henrichs et al., 2011)

367 also reported that children who showed a declining trajectory were more likely to have mothers

368 with a low educational level. The effect of alcohol consumption during pregnancy (depending on

369 dose, duration, and pattern of drinking) on the cognitive development of the child is well

370 supported by the scientific literature (Larroque et al., 1995; O’Leary et al., 2009). Even in 
371 children born after 37 weeks (only $2.2 \%$ of the children were born preterm in our sample),

372 associations between birth term and cognitive development have been reported (Yang, Platt, \&

373 Kramer, 2010). Many studies have shown that breastfeeding was associated with better language

374 skills in children (Whitehouse et al., 2011; Bernard et al., 2013). In our study, the effects of

375 alcohol consumption during pregnancy, birth term and breastfeeding seem to be partly delayed.

376 These results contrast with the intuitive idea that such biological factors show mostly early

377 influences (i.e., up to 2 years), and that social factors rather have later influences. In fact it is

378 perfectly possible that some biological factors may show increasing effects when language

379 abilities become more elaborated (i.e., between 2 and 3 years).

381 The strengths of the EDEN study include its longitudinal design with repeated measurements of

382 language development. Although the language measure at 2 years was based solely on parental

383 report of expressive vocabulary, the measures at 3 years were made by trained clinicians using

384 several tests tapping multiple relevant dimensions of language (vocabulary, phonology, syntax).

385 Whereas the richness of the 3-year-old measures is a strength, the qualitative differences between

386 language measures at the two time points is a limitation, thus estimates of the increase of variance

387 explained by risk factors between 2 and 3 years needs to be interpreted cautiously. There was also

388 evidence for some selective bias due to missing data; indeed, children whose data were available

389 at both ages had better language skills at 2 years and fewer risk factors for language delay than

390 children with missing LC-3 or CDI-2 (see Supplementary Table). Such a bias reduces the

391 variance of our sample and therefore the statistical power of our analysis.

392

393 Our ability to predict which toddlers have language delay at 3 years remains modest at best. As

394 language skills are still unstable after 3 years (as shown by the study of Law et al. (2012)), 
395

396

397

398

399

400

401

402

403

404

405

406

407

408

409

410

411

412

\section{Acknowledgements}

414 - We are indebted to the participating families, the midwife research assistants (L Douhaud, S

415 Bedel, B Lortholary, S Gabriel, M Rogeon, and M Malinbaum) for data collection, the 416 psychologists (Marie-Claire Cona and Marielle Paquinet) and P Lavoine, J Sahuquillo and G 417 Debotte for checking, coding, and data entry. We also thank S Kern for providing the French 418 version of the MacArthur Communicative Development Inventory. 
419 - Members of the EDEN mother-child cohort study group are as follows: MA Charles, M De 420 Agostini, A Forhan, B Heude and P Ducimetière (INSERM, UMR-S 1018, Team 10); M 421 Kaminski, MJ Saurel-Cubizolles, P Dargent, X Fritel, B Larroque, N Lelong, L Marchand, and C 422 Nabet (INSERM, U953); I Annesi-Maesano (INSERM U707); R Slama (INSERM, U953); V 423 Goua, G Magnin and R Hankard (Poitiers University Hospital); O Thiebaugeorges, M 424 Schweitzer, B Foliguet (Nancy University Hospital); and N Job-Spira (ANRS).

425

426

427

\section{References}

428

Bernard, J. Y., De Agostini, M., Forhan, A., Alfaiate, T., Bonet, M., Champion, V., Kaminski, M., 430 de Lauzon-Guillain, B., Charles, M.-A., Heude, B., et al. 2013. Breastfeeding duration and 431 cognitive development at 2 and 3 years of age in the EDEN mother-child cohort. The Journal of 432 pediatrics 163(1):3642.e1.

433 Bishop, D. V. M., Price, T. S., Dale, P. S., \& Plomin, R. 2003. Outcomes of early language delay: 434 II. Etiology of transient and persistent language difficulties. Journal of speech, language, and 435 hearing research: JSLHR 46(3):561575.

436 Blondel, B., Supernant, K., Du Mazaubrun, C., \& Breart, G. 2006. Trends in perinatal health in 437 metropolitan France between 1995 and 2003: results from the National Perinatal Surveys. J 438 Gynecol Obstet Biol Reprod (Paris) 35:373387.

439 Dale, P. S., Price, T. S., Bishop, D. V. M., \& Plomin, R. 2003. Outcomes of early language delay: 440 I. Predicting persistent and transient language difficulties at 3 and 4 years. Journal of speech, 441 language, and hearing research: JSLHR 46(3):544560.

442 De Agostini, M., Metz-Lutz, M.-N., Van Hout, A., Chavance, M., Deloche, G., Pavao-Martins, I., 443 \& Dellatolas, G. 1998. Batterie d'évaluation du langage oral de l'enfant aphasique (ELOLA) : 444 standardisation française (4-12 ans). In Revue de neuropsychologie (Vol. 8, p. 319367). Présenté 445 à Société de Neuropsychologie de Langue Française. Journées, ADRSC. 
446 Drouillet, P., Forhan, A., De Lauzon-Guillain, B., Thiébaugeorges, O., Goua, V., Magnin, G., 447 Schweitzer, M., Kaminski, M., Ducimetière, P., \& Charles, M.-A. 2009. Maternal fatty acid 448 intake and fetal growth: evidence for an association in overweight women. The " EDEN mother449 child » cohort (study of pre-and early postnatal determinants of the child's development and 450 health). The British journal of nutrition 101(4):583591.

451 Farah, M. J., Betancourt, L., Shera, D. M., Savage, J. H., Giannetta, J. M., Brodsky, N. L., 452 Malmud, E. K., \& Hurt, H. 2008. Environmental stimulation, parental nurturance and cognitive 453 development in humans. Developmental science 11(5):793801.

454 Feldman, H. M., Dale, P. S., Campbell, T. F., Colborn, D. K., Kurs-Lasky, M., Rockette, H. E., \& 455 Paradise, J. L. 2005. Concurrent and predictive validity of parent reports of child language at 456 ages 2 and 3 years. Child development 76(4):856868.

457 Henrichs, J., Rescorla, L., Schenk, J. J., Schmidt, H. G., Jaddoe, V. W. V., Hofman, A., Raat, H., 458 Verhulst, F. C., \& Tiemeier, H. 2011. Examining continuity of early expressive vocabulary 459 development: the generation R study. Journal of speech, language, and hearing research: JSLHR 460 54(3):854869.

461 Kemp, S. L., Kirk, U., \& Korkman, M. 2001. Essentials of NEPSY Assessment (1 ${ }^{\text {re }}$ éd.). Wiley.

462 Kern, S. 2003. Le compte-rendu parental au service de l'évaluation de la production lexicale des 463 enfants français entre 16 et 30 mois. Paris, France: Union nationale pour le développement de la 464 recherche et de l'information en orthophonie.

465 Kern, S., Langue, J., Zesiger, P., \& Bovet, F. 2010. Adaptations françaises des versions courtes 466 des inventaires du développement communicatif de MacArthur-Bates. Approche 467 Neuropsychologique des Apprentissages chez l'Enfant 107-108:217228.

468 Korkman M, Kirk U, \& Kemp S. 2003. Nepsy Bilan Neuropsychologique de l'enfant. Paris: 469 ECPA (Editions du Centre de Psychologie Appliquée).

470 Larroque, B., Kaminski, M., Dehaene, P., Subtil, D., Delfosse, M. J., \& Querleu, D. 1995.

471 Moderate prenatal alcohol exposure and psychomotor development at preschool age. American 472 Journal of Public Health 85(12):16541661. 
473 Law, J., Garrett, Z., \& Nye, C. 2003. Speech and language therapy interventions for children

474 with primary speech and language delay or disorder. Cochrane database of systematic reviews 475 (Online) (3):CD004110.

476 Law, J., Rush, R., Anandan, C., Cox, M., \& Wood, R. 2012. Predicting language change between 4773 and 5 years and its implications for early identification. Pediatrics 130(1):e132137.

478 Mäntynen, H., Poikkeus, A. M., Ahonen, T., Aro, T., \& Korkman, M. 2001. Clinical significance 479 of test refusal among young children. Child neuropsychology: a journal on normal and abnormal 480 development in childhood and adolescence 7(4):241250.

481 Nelson, H. D., Nygren, P., Walker, M., \& Panoscha, R. 2006. Screening for speech and language 482 delay in preschool children: systematic evidence review for the US Preventive Services Task 483 Force. Pediatrics 117(2):e298319.

484 O’Leary, C., Zubrick, S. R., Taylor, C. L., Dixon, G., \& Bower, C. 2009. Prenatal alcohol 485 exposure and language delay in 2-year-old children: the importance of dose and timing on risk. 486 Pediatrics 123(2):547554.

487 Reilly, S., Wake, M., Ukoumunne, O. C., Bavin, E., Prior, M., Cini, E., Conway, L., Eadie, P., \& 488 Bretherton, L. 2010. Predicting language outcomes at 4 years of age: findings from Early 489 Language in Victoria Study. Pediatrics 126(6):e15301537.

490 Rice, M. L., Taylor, C. L., \& Zubrick, S. R. 2008. Language outcomes of 7-year-old children with 491 or without a history of late language emergence at 24 months. Journal of speech, language, and 492 hearing research: JSLHR 51(2):394407.

493 Westerlund, M., Berglund, E., \& Eriksson, M. 2006. Can severely language delayed 3-year-olds 494 be identified at 18 months? Evaluation of a screening version of the MacArthur-Bates 495 Communicative Development Inventories. Journal of speech, language, and hearing research: 496 JSLHR 49(2):237247.

497 Whitehouse, A. J. O., Robinson, M., Li, J., \& Oddy, W. H. 2011. Duration of breast feeding and 498 language ability in middle childhood. Paediatric and perinatal epidemiology 25(1):4452. 
499 Yang, S., Platt, R. W., \& Kramer, M. S. 2010. Variation in Child Cognitive Ability by Week of

500 Gestation Among Healthy Term Births. American Journal of Epidemiology 171(4):399406.

501 Zubrick, S. R., Taylor, C. L., Rice, M. L., \& Slegers, D. W. 2007. Late language emergence at 24

502 months: an epidemiological study of prevalence, predictors, and covariates. Journal of speech, 503 language, and hearing research: JSLHR 50(6):15621592.

504 
Figure 1 (on next page)

Figure 1: Flowchart. 


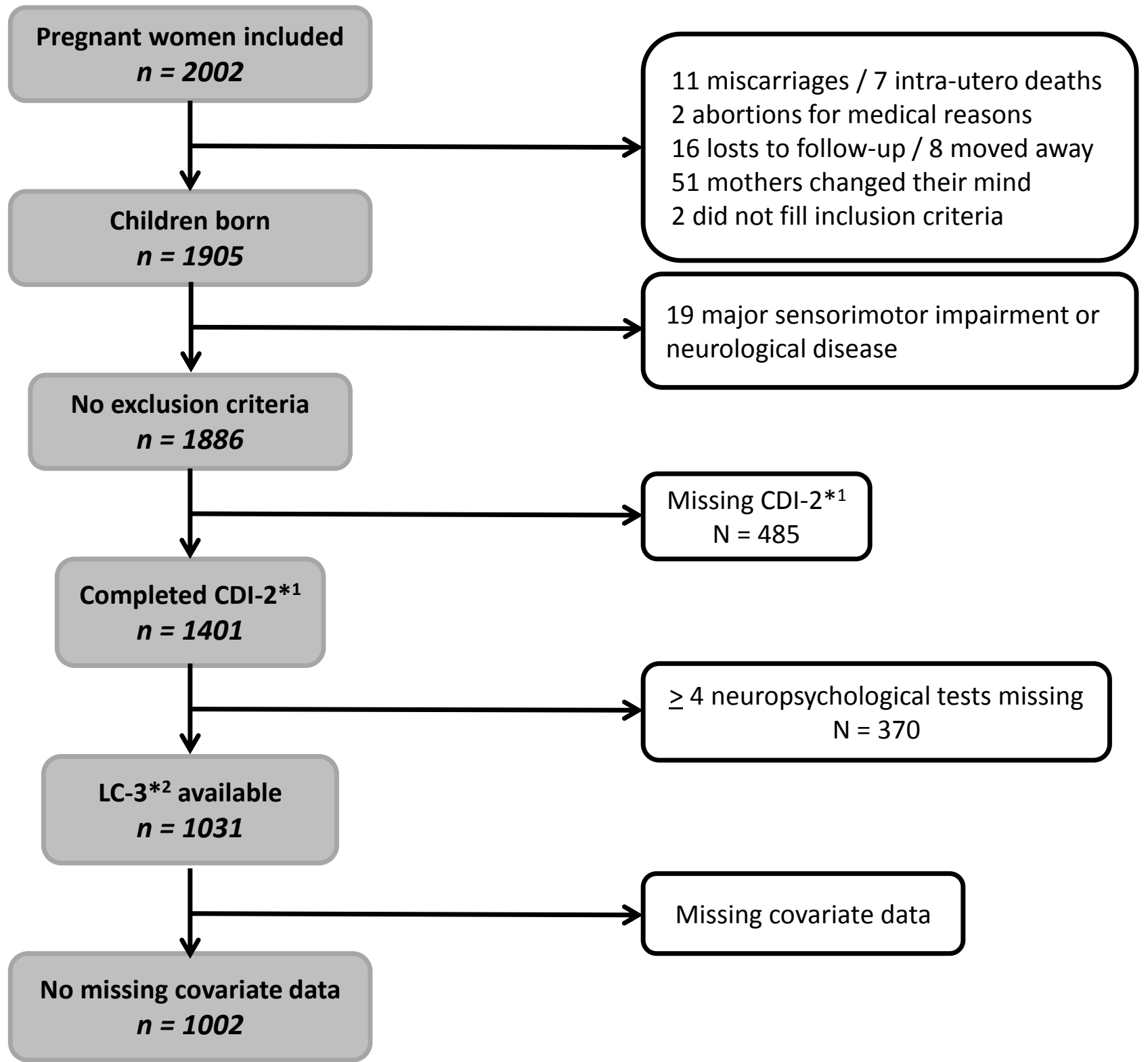

*1 CDI-2: MacArthur Communicative Development Inventory at 2 years. PeerJ reviewing PDF I (v2013:11:1056:2:0:NEW 16 Mar 2014 ${ }^{* 2}$ LC-3: Language component at 3 years. 


\section{Table 1 (on next page)}

Table 1: Summary statistics of the participating children [mean (SD) or N (\%)].

\# On a scale of 1 (shared activities less than once per week) to 5 (shared activities nearly every day). The frequency of maternal stimulation between 0 and 3 years correspond to the average of this measure between 0 and 2 years and between 2 and 3 years. Abbreviations: CDI-2: MacArthur Communicative Development Inventory at 2 years. LC-3: Language component at 3 years. SD: Standard deviation. 
Table 1: Summary statistics of the participating children [mean (SD) or N (\%)].

\begin{tabular}{|c|c|c|c|c|c|}
\hline & $\begin{array}{l}\text { Total sample } \\
(\mathrm{N}=1002)\end{array}$ & $\begin{array}{c}\text { Typical Language } \\
\text { group } \\
(\mathrm{N}=843)\end{array}$ & $\begin{array}{c}\text { Resilient Language } \\
\text { group } \\
(\mathrm{N}=59)\end{array}$ & $\begin{array}{c}\text { Increasingly } \\
\text { Vulnerable Language } \\
\text { group } \\
(\mathrm{N}=59) \\
\end{array}$ & $\begin{array}{c}\text { Consistently Low } \\
\text { Language group } \\
\text { (N=41) }\end{array}$ \\
\hline \multicolumn{6}{|c|}{ (1i 00$)$} \\
\hline Male gender, $N(\%)$ & $520(52)$ & $423(50)$ & $39(66)$ & $33(56)$ & $25(61)$ \\
\hline Birth weight, $\mathrm{kg}$ & $3.30(0.49)$ & $3.31(0.47)$ & $3.36(0.50)$ & $3.17(0.54)$ & $3.24(0.58)$ \\
\hline Birth term, weeks & $39.30(1.65)$ & $38.93(2.17)$ & $38.69(2.04)$ & $39.17(1.99)$ & $39.37(1.55)$ \\
\hline \multicolumn{6}{|l|}{ Mother } \\
\hline Maternal age at birth of child, years & $29.52(4.67)$ & $29.49(4.72)$ & $30.49(4.41)$ & $28.83(4.38)$ & $29.73(4.35)$ \\
\hline Alcohol during pregnancy (>3 units/week), $1 \%$ (\%) & $79(8)$ & $61(7)$ & $7(12)$ & $9(15)$ & $2(5)$ \\
\hline Tobacco during pregnancy, $N(\%)$ & $209(21)$ & $171(20)$ & $13(22)$ & $16(27)$ & $9(22)$ \\
\hline Initiation, $N(\%) \quad \geq$ & $731(73)$ & $630(75)$ & $44(75)$ & $39(66)$ & $18(44)$ \\
\hline Duration, months & $4.71(3.74)$ & $4.81(3.75)$ & $4.15(3.65)$ & $3.87(3.41)$ & $4.45(4.20)$ \\
\hline \multirow{2}{*}{\multicolumn{6}{|c|}{ Child's environment }} \\
\hline \multicolumn{2}{|l|}{ Household income (euros), $N(\%)$} & & & & \\
\hline$<2300$ & $403(40)$ & $318(38)$ & $26(44)$ & $34(58)$ & $25(61)$ \\
\hline $2300-3000$ & $298(30)$ & $258(31)$ & $14(24)$ & $15(25)$ & $11(27)$ \\
\hline$>3000$ & $301(30)$ & $267(32)$ & 19 (32) & $10(17)$ & $5(12)$ \\
\hline Parental education, years & $13.70(2.29)$ & $13.88(2.26)$ & $13.42(2.30)$ & $12.40(1.92)$ & $14.43(2.18)$ \\
\hline \multicolumn{6}{|l|}{ Caretaker, $N(\%)$} \\
\hline Family & $94(9)$ & $70(8)$ & $10(17)$ & $7(12)$ & $7(17)$ \\
\hline Mother & $214(21)$ & 160 (19) & $17(29)$ & $22(37)$ & $15(37)$ \\
\hline \multicolumn{6}{|l|}{ Number of older siblings, $\mathrm{N}(\%)$} \\
\hline 0 & 489 (49) & $434(51)$ & $21(36)$ & $21(36)$ & $13(32)$ \\
\hline 1 & $344(34)$ & 278 (33) & $25(42)$ & $22(37)$ & $19(46)$ \\
\hline$>1$ & $169(17)$ & $131(16)$ & $13(22)$ & $16(27)$ & $9(22)$ \\
\hline Bilingualism, $N(\%)$ & $94(9)$ & $82(10)$ & $6(10)$ & $5(8)$ & $1(2)$ \\
\hline \multicolumn{6}{|l|}{ Frequency of maternal stimulation ${ }^{\#}$} \\
\hline between $0-2$ years & $3.32(0.72)$ & $3.35(0.69)$ & $3.23(0.80)$ & $3.18(0.77)$ & $2.94(0.98)$ \\
\hline between 2-3 years & $3.19(0.71)$ & $3.25(0.67)$ & $2.95(0.79)$ & $2.86(0.80)$ & $2.83(0.85)$ \\
\hline between $0-3$ years & $3.26(0.61)$ & $3.30(0.58)$ & $3.09(0.69)$ & $3.02(0.67)$ & $2.89(0.81)$ \\
\hline \multicolumn{6}{|l|}{ Pre-elementary schooled } \\
\hline Yes, $N(\%)$ & $676(67)$ & $584(69)$ & $29(49)$ & $36(61)$ & $27(66)$ \\
\hline School attendance, months & $3.14(3.35)$ & $3.18(3.28)$ & $2.67(3.71)$ & $2.54(3.05)$ & $3.81(4.32)$ \\
\hline \multicolumn{6}{|l|}{ Language measures } \\
\hline $\mathrm{CDI}-2$ & $61.03(28.80)$ & $69.88(24.21)$ & $13.27(5.66)$ & $41.19(17.36)$ & $10.80(5.52)$ \\
\hline LC-3 & $0.01(1.01)$ & $0.28(0.78)$ & $-0.46(0.59)$ & $-1.84(0.41)$ & $-2.16(0.54)$ \\
\hline Semantic fluency & $6.83(3.94)$ & $7.54(3.67)$ & $4.87(3.31)$ & $1.79(2.07)$ & $1.44(1.59)$ \\
\hline Word and nonword repetition & $7.60(3.24)$ & $8.37(2.64)$ & $5.48(3.37)$ & $2.89(2.31)$ & $1.68(1.98)$ \\
\hline Sentence comprehension & $8.63(2.96)$ & $9.17(2.61)$ & $8.17(2.46)$ & $4.46(2.49)$ & $4.10(2.26)$ \\
\hline Sentence repetition & $7.21(3.35)$ & $7.80(3.12)$ & $5.75(2.69)$ & $3.23(2.08)$ & $2.38(1.75)$ \\
\hline
\end{tabular}




\section{Table 2 (on next page)}

Table 2: Factors predicting language performance at 2, 3 and between 2 and 3 years $(\mathrm{N}=1002)$.

\# On a scale of 1 (shared activities less than once per week) to 5 (shared activities nearly every day). The frequency of maternal stimulation between 0 and 2 years was used in model A1, between 0 and 3 years in model A2 and between 2 and 3 years in model A3. Abbreviations: CDI-2: MacArthur Communicative Development Inventory at 2 years. LC-3: Language component at 3 years. $\beta$ : Regression coefficient with $95 \%$ confidence interval $(95 \% \mathrm{Cl}) \cdot \mathrm{p}=\mathrm{p}$-value. $\mathrm{R}^{2}$ : Coefficient of determination. 
Table 2: Factors predicting language performance at 2, 3 and between 2 and 3 years $(\mathrm{N}=1002)$.

\begin{tabular}{|c|c|c|c|c|c|c|}
\hline \multirow{3}{*}{$\begin{array}{l}\text { Dependent variable } \\
\text { Independent variables }\end{array}$} & \multicolumn{2}{|c|}{ Model A1 } & \multicolumn{2}{|c|}{ Model A2 } & \multicolumn{2}{|c|}{ Model A3 } \\
\hline & \multicolumn{2}{|c|}{$\begin{array}{c}\text { CDI-2 } \\
\text { Risk factors } \\
R^{2}=15.6 \%\end{array}$} & \multicolumn{2}{|c|}{$\begin{array}{c}\text { LC-3 } \\
\text { Risk factors } \\
R^{2}=\mathbf{2 1 . 0} \%\end{array}$} & \multicolumn{2}{|c|}{$\begin{array}{c}\text { LC-3 } \\
\text { CDI-2 and risk factors } \\
\mathbf{R}^{\mathbf{2}}=\mathbf{4 3 . 4 \%}\end{array}$} \\
\hline & $\beta$ & $p$ & $\beta$ & $p$ & $\beta$ & $p$ \\
\hline \multicolumn{7}{|l|}{ Child } \\
\hline Male gender & -7.55 & $<0.001$ & -0.30 & $<0.001$ & -0.16 & 0.001 \\
\hline Birth weight, $k g$ & 2.53 & 0.3 & 0.12 & 0.1 & 0.09 & 0.2 \\
\hline Birth term, weeks & 1.81 & 0.005 & 0.05 & 0.03 & 0.01 & 0.47 \\
\hline \multicolumn{7}{|l|}{ Mother } \\
\hline Maternal age at birth of childinyears & -0.12 & 0.6 & 0.01 & 0.3 & 0.01 & 0.08 \\
\hline Alcohol during pregnancy ( $>3$ units/week) & -6.07 & $<0.001$ & -0.13 & 0.2 & -0.03 & 0.8 \\
\hline Tobacco during pregnancy & 1.11 & 0.6 & -0.01 & 0.9 & -0.01 & 0.6 \\
\hline Family history of language delay & -4.98 & 0.06 & -0.19 & 0.03 & -0.10 & 0.2 \\
\hline Breastfeeding Initiation & 4.86 & 0.02 & 0.15 & 0.03 & 0.06 & 0.3 \\
\hline \multicolumn{7}{|l|}{ Child's environment } \\
\hline Household income (euros) $>$ & & 0.3 & & 0.1 & & 0.04 \\
\hline$<2300$ & -2.22 & & -0.16 & & -0.11 & \\
\hline $2300-3000$ & 1.40 & & -0.16 & & -0.17 & \\
\hline$>3000$ & ref. & & ref. & & ref. & \\
\hline Parental education, years & 0.75 & 0.1 & 0.09 & $<0.001$ & 0.08 & $<0.001$ \\
\hline Caretaker & & $<0.001$ & & 0.006 & & 0.4 \\
\hline Nursery & 6.86 & & 0.12 & & 0.00 & \\
\hline Other & 8.41 & & 0.20 & & 0.06 & \\
\hline Family & -1.02 & & -0.12 & & -0.09 & \\
\hline Mother & ref. & & ref. & & ref. & \\
\hline Number of older siblings & & 0.2 & & 0.1 & & 0.2 \\
\hline 0 & ref. & & ref. & & ref. & \\
\hline 1 & -3.89 & & -0.11 & & -0.04 & \\
\hline$>1$ & -2.68 & & -0.18 & & -0.15 & \\
\hline Bilingualism & 2.89 & 0.3 & 0.05 & 0.6 & 0.00 & 1 \\
\hline \multicolumn{7}{|l|}{ Frequency of maternal stimulation" } \\
\hline between $0-2$ years & 8.79 & $<0.001$ & - & - & - & - \\
\hline between 2-3 years & - & - & - & - & 0.09 & 0.02 \\
\hline between $0-3$ years & - & - & 0.27 & $<0.001$ & - & - \\
\hline Pre-elementary schooled & - & - & 0.14 & 0.03 & 0.09 & 0.09 \\
\hline Recruitement centre (Poitiers) & -0.35 & 0.8 & -0.03 & 0.6 & -0.02 & 0.7 \\
\hline Language measures & & & & & & \\
\hline CDI-2 & - & - & - & - & 0.02 & $<0.001$ \\
\hline
\end{tabular}

" On a scale of 1 (shared activities less than once per week) to 5 (shared activities nearly every day). The frequency of maternal stimulation between 0 and 2 years was used in model A1, between 0 and 3 years in Abbreviations: CDI-2: MacArthur Communicative Development Inventory at 2 years. LC-3: Language component at 3 years. $\beta$ : Regression coefficient with $95 \%$ confidence interval (95\% Cl). $p=p$-value. $\mathrm{R}^{2}:$ Coefficient of determination. 


\section{Table 3(on next page)}

Table 3: Factors associated with the resilient trajectory (model B1: Resilient Language group vs. Consistently Low Language group) and the declining trajectory (model B2: Increasingly Vulnerable Language group vs. Typical Language group).

\# On a scale of 1 (shared activities less than once per week) to 5 (shared activities nearly every day). The variable frequency of maternal stimulation between 2 and 3 years was used in models B1 and B2. Abbreviations: OR: Odds ratios with $95 \%$ confidence interval $(95 \%$ $\mathrm{Cl}) / \mathrm{p}=\mathrm{p}$-value (in bold if $\mathrm{p}<0.05$ ). 
Table 3: Factors associated with the resilient trajectory (model B1: Resilient Language group vs. Consistently Low Language group) and the declining trajectory (model B2: Increasingly Vulnerable Language group $v s$. Typical Language group).

\begin{tabular}{|c|c|c|c|c|c|c|c|c|}
\hline \multirow[b]{4}{*}{ Alcohol during pregnancy ( $>3$ units/week) } & \multicolumn{4}{|c|}{ Model B1 } & \multicolumn{4}{|c|}{ Model B2 } \\
\hline & \multicolumn{4}{|c|}{$\begin{array}{c}\text { Resilient Language } \\
\text { vs } \\
\text { Consistently Low Language }\end{array}$} & \multicolumn{4}{|c|}{$\begin{array}{c}\text { Increasingly Vulnerable Language } \\
\text { vs } \\
\text { Typical Language }\end{array}$} \\
\hline & \multirow{2}{*}{$\begin{array}{c}\text { OR } \\
-\end{array}$} & \multicolumn{2}{|c|}{$95 \% \mathrm{Cl}$} & \multirow{2}{*}{$p$} & \multirow{2}{*}{$\frac{\text { OR }}{2.29}$} & \multicolumn{2}{|c|}{$95 \% \mathrm{Cl}$} & \multirow{2}{*}{$\begin{array}{c}p \\
0.04\end{array}$} \\
\hline & & - & - & & & 1.04 & -5.02 & \\
\hline Breastfeeding initiation & 3.75 & 1.60 & -8.78 & 0.002 & - & - & - & - \\
\hline Birth term, weeks & - & - & - & - & 0.81 & 0.71 & -0.93 & $<0.001$ \\
\hline Parental education, years & - & - & - & - & 0.76 & 0.67 & - 0.87 & $<0.001$ \\
\hline Frequency of maternal stimulation ${ }^{\#}$ & - & - & - & - & 0.52 & 0.37 & -0.75 & 0.001 \\
\hline
\end{tabular}

\# On a scale of 1 (shared activities less than once per week) to 5 (shared activities nearly every day). The variable frequency of maternal stimulation between 2 and 3 years was used in models B1 and B2.

Abbreviations: OR: Odds ratios with $95 \%$ confidence interval $(95 \% \mathrm{Cl}) / p=p$-value (in bold if $p<0.05$ ). 